\title{
Medicaid and the Uninsured
}

\section{Relationship between State Medicaid Policies, Nursing Home Racial Composition, and the Risk of Hospitalization for Black and White Residents}

\author{
Andrea Gruneir, Susan C. Miller, Zhanlian Feng, Orna Intrator, \\ and Vincent Mor
}

Objective. To examine racial differences in the risk of hospitalization for nursing home $(\mathrm{NH})$ residents.

Data Sources. National NH Minimum Data Set, Medicare claims, and Online Survey Certification and Reporting data from 2000 were merged with independently collected Medicaid policy data.

Study Design. One hundred and fifty day follow-up of 516,082 long-stay residents. Principle Findings. 18.5 percent of white and 24.1 percent of black residents were hospitalized. Residents in NHs with high concentrations of blacks had 20 percent higher odds (95 percent confidence interval $[\mathrm{CI}]=1.15-1.25)$ of hospitalization than residents in NHs with no blacks. Ten-dollar increments in Medicaid rates reduced the odds of hospitalization by 4 percent $(95$ percent $\mathrm{CI}=0.93-1.00)$ for white residents and 22 percent (95 percent $\mathrm{CI}=0.69-0.87$ ) for black residents.

Conclusions. Our findings illustrate the effect of contextual forces on racial disparities in NH care.

Key Words. Nursing home, Medicaid, racial disparities

Racial disparities in the quality of nursing home (NH) care have been well documented. Black residents are less likely than their white counterparts to receive appropriate pharmacologic management for a myriad of conditions (Bernabei et al. 1998; Gambassi et al. 1998; Lapane, Fernandez, and Friedman 1999; Won et al. 1999; Spooner et al. 2001) and less likely to receive physical therapy upon admission (Harada et al. 2000). Black residents are also more likely to be hospitalized than are white residents (Culler, Parchman, and 
Przybylski 1998). Even at the end-of-life, the risk of hospitalization for black residents, especially older or functionally impaired residents, is higher than for white residents (Mor, Papandonatos, and Miller 2005). This has been partially attributed to an apparent preference for more aggressive care among blacks that may be related to concerns about undertreatment (Caralis, Davis, and Wright 1993; Dula 1994; O'Brien et al. 1995; Shepardson et al. 1999; Hopp and Duffy 2000; Degenholtz et al. 2002; Mitchell et al. 2007).

Yet, individual preferences are not the sole risk factor for hospitalization. Facility characteristics, such as staffing and payer mix, have also been shown to be associated with hospitalization (Intrator, Castle, and Mor 1999; Intrator, Zinn, and Mor 2004; Mor, Papandonatos, and Miller 2005). This is particularly important in light of $\mathrm{NH}$ segregation by race and resources. Quality $\mathrm{NH}$ care is dependent on the availability of resources (Mor et al. 2004; Miller et al. 2006) but NHs that are largely Medicaid-reliant are often disadvantaged because Medicaid rates are generally below private pay rates and sometimes below actual costs of care (Seidman 2002). Such facilities disproportionately serve black residents (Mor et al. 2004).

Studies have shown a persistent association between state Medicaid reimbursement policies and hospitalization. Ten dollar differences in per diem Medicaid rates are associated with a 5-9 percent decrease in individual risk of hospitalization (Intrator and Mor 2004) while the presence of a bed hold policy is associated with an increased risk of hospitalization by nearly 40 percent (Intrator et al. 2007; Gruneir et al. 2007). Whether the effects of these policies differ for black and white residents has never been examined. Given the concentration of black residents in NHs that are characterized by reliance on Medicaid, this presents an important question (Smith et al. 2007).

The purpose of this study is to quantify the effect of Medicaid reimbursement policies, facility racial composition, and specific resident characteristics on the differential risk of hospitalization for black and white $\mathrm{NH}$ residents. We examined the effect of the average Medicaid per diem rate and the presence of a bed hold policy in each state. We also examined the risk of

Address correspondence to Andrea Gruneir, Ph.D., Kunin-Lunenfeld Applied Research Unit, Baycrest Centre for Geriatric Care, Toronto, ON M6A 2E1 (Canada). Susan C. Miller, Ph.D., and Vincent Mor, Ph.D., are with the Center for Gerontology and Health Care Research and the Department of Community Health, Brown University, Providence, RI. Zhanlian Feng, Ph.D., and Orna Intrator, Ph.D., are with the Center for Gerontology and Health Care Research, Brown University, Providence, RI. 
hospitalization for residents in NHs with varying proportions of black residents and for residents who were older and more functionally impaired.

\section{METHODS}

This study is a subanalysis of data presented by Intrator et al. (2007). We provide a brief description of the methods, which are fully described in the main paper (Intrator et al. 2007).

\section{Data Sources}

Data from five sources were merged to create a hierarchical database. Resident data were obtained from the Minimum Data Set (MDS), a federally mandated assessment instrument (Mor 2004), and Medicare inpatient files. $\mathrm{NH}$ data were obtained from the Online Survey Certification and Reporting (OSCAR) database, which consists of the annually collected surveys required for certified NHs. The area resource file (ARF) was used to characterize the market, which was defined as the county (Banaszak-Holl, Zinn, and Mor 1996). Finally, we obtained data on Medicaid reimbursement policies from a survey of state Medicaid offices conducted by the Center for Gerontology and Health Care Research at Brown University (Grabowski et al. 2004).

\section{Study Sample}

The sample consisted of all urban markets in the continental United States. Inclusion of NHs was restricted to those that were free-standing and had at least 20 beds. This resulted in a total of $8,997 \mathrm{NHs}$ in 813 counties.

Resident assessments were selected from the second quarter of 2000. Inclusion was restricted to residents who were long-stay (over 90 days) and older than age 65 . Residents were excluded if they were in a coma, in a swingbed facility, enrolled in an HMO during 2000 (for completeness of claims), or could not be matched to Medicare claims. Of all 1,740,074 residents in 2000, 572,557 met these inclusion criteria.

\section{Outcome: Hospitalization}

Medicare data were used to identify residents who were hospitalized or who died (whichever came first) within 150 days of the baseline assessment. When there was no evidence of $\mathrm{NH}$ discharge, we assumed that the resident remained in the facility. We distinguished between residents who died (but were not hospitalized) and residents who remained in the $\mathrm{NH}$ because they likely 
differed on unobserved characteristics associated with hospitalization. There were 54,870 (9.6 percent) residents who died but were not hospitalized during follow-up.

\section{Determinants}

State Policies. We examined average per diem Medicaid reimbursement and the presence of a bed hold policy. In multivariable analyses, payment rates were standardized to a $\$ 100$ mean and $\$ 10$ increments. A bed hold policy guarantees that Medicaid will pay some portion of the per diem rate to the $\mathrm{NH}$ if the resident is hospitalized. We grouped all states that had any form of bed hold policy into a single category.

Resident Race. Individual race was taken from the MDS and residents were classified as either non-Hispanic white, non-Hispanic black, or other. The "other" group consisted of residents identified as Hispanic, Asian/Pacific Islander, and American Indian/Alaskan native. We combined these groups into one category because they account for a small proportion of residents (4.1 percent).

NH Racial Composition. We categorized NHs by the percent of all residents that were identified as non-Hispanic black. Using the distribution quartiles, we created an ordinal variable with the following cut-offs: $0-0.83,0.84-3.6$, $3.7-12.9,13$ percent and greater.

Modifiers of the Effect of Race. Based on prior research (Mor, Papandonatos, and Miller 2005), we chose to test age and functional ability as effect measure modifiers. In the multivariable model, age was centered at the mean (84 years) and standardized to 10-year increments. Functional status was measured on a six-point scale of the resident's ability to perform activities of daily living (ADLs) (Morris, Fries, and Morris 1999). We categorized residents as having: no or mild impairment (0-1), moderate impairment (2-3), and severe impairment (4-5).

Final estimates were adjusted for several potential confounders. Resident-level confounders included gender, education, do not resuscitate (DNR) and do not hospitalize (DNH) orders, weight categories, cognitive impairment (measured on the Cognitive Performance Scale [Morris et al. 1994]), diagnoses (diabetes, cancer, emphysema/COPD, and heart failure), 
unstable medical condition, fever, more than nine prescribed medications, use of antipsychotic or hypnotic medications, and hospice enrollment.

Facility-level characteristics that were controlled for included: staffing (nurse practitioner or physician assistant, physician presence, nursing hours per resident day, and registered nurse presence), number of beds, profit status, chain membership, percent of residents on each Medicaid ( $>85$ percent), Medicare ( $>15$ percent), and private pay ( $>35$ percent), and occupancy ( $>90$ percent). Aggregated MDS data were used to calculate mean case-mix index (Fries et al. 1994).

Market variables included: per capita income, percent of population older than 75 years, number of hospital beds per 1,000 persons older than 75 years, and adjusted hospital wage index. Market competitiveness was quantified by the Herfindahl index and dichotomized at 0.1 to identify highly competitive markets (Zinn 1994).

\section{Analytic Design}

We used descriptive statistics to characterize the sample and a multilevel model to estimate effect sizes and standard errors. We modeled the odds of being hospitalized against the odds of remaining in the $\mathrm{NH}$ and censored residents who died during follow-up; the same strategy was used in the main study (Intrator et al. 2007).

Differential effects of race were estimated with multiplicative interaction terms. We included interactions between resident race and each age, ADL status, and state Medicaid rate. We had tested interactions between race and bed hold policy but decided not to include them because there was no evidence of a differential effect. Because of the uneven distribution of NHs that served predominantly black residents across states (10 states had no NHs in the top quartile), we chose not to include interactions between $\mathrm{NH}$ racial composition and state policies. Descriptive statistics were carried out in $S A S$ (Research Triangle Institute Inc., Research Triangle Park, NC) and the multilevel model was estimated with $M L W i N$ (Multilevel Models Project, Institute of Education, University of London, London, U.K.).

\section{RESUlTS}

Of the 517,687 residents who met the inclusion criteria and did not die during follow-up, 1,605 had missing data (most commonly: DNR/DNH [1,009], 
diagnoses [469], and race [143]). Of the remaining 516,082 residents, a total of 19.3 percent were hospitalized, 18.5 percent of white and 24.1 percent of black residents. The sample was largely female and older than 75 .

Table 1: Characteristics of Long-Stay Nursing Home Residents Who Were Either Hospitalized or Remained in the Nursing Home by the End of the 150 Day Follow-up Period $(N=516,082)$

Percent

Outcome

Hospitalized

Demographics

Age, years

$65-74$

13.4

$75-84$

36.6

85-94

41.8

$95+$

Female

Race

African American

White

Other

Education

Less than high school

High school

More than high school

Unknown

Functional status

Cognitive impairment

None/mild

Moderate

Severe

Physical impairment (ADL)

None/mild

Moderate

Severe

Unstable condition

Diagnoses

Diabetes

Heart failure

Emphysema/COPD

Cancer

Preferences

Do not hospitalize 
Eleven percent of residents were black and 4 percent were identified as "other." A minority of residents had minimal ADL impairment (14.3 percent) and the remainder was split between moderate and severe impairment (Table 1).

A full description of facility and market characteristics are available from Intrator et al. (2007). Across NHs, the mean percent of residents identified as black was $11.4(\mathrm{SD}=18.4)$ but the distribution was highly skewed; nearly 25 percent of NHs had fewer than 1 percent of residents identified as black while the top percentile reported over 87 percent of residents identified as black (not shown). When stratified by quartiles of the percent of residents identified as black, clear trends in NH ownership, staffing, and resource availability emerged (Table 2).

Table 2: Characteristics of Nursing Homes by the Percent of Residents Identified as Black (Divided into Distribution Quartiles)

\begin{tabular}{|c|c|c|c|c|}
\hline & $\begin{array}{c}\text { 1st Quartile } \\
\text { (Lowest } \\
\text { Percent) }\end{array}$ & $\begin{array}{c}2 n d \\
\text { Quartile }\end{array}$ & $\begin{array}{c}3 r d \\
\text { Quartile }\end{array}$ & $\begin{array}{c}\text { 4th Quartile } \\
\text { (Highest } \\
\text { Percent) }\end{array}$ \\
\hline \multicolumn{5}{|l|}{ Ownership } \\
\hline For-profit, $\%$ & 56.8 & 72.8 & 82.4 & 83.1 \\
\hline Part of a chain, $\%$ & 51.0 & 59.2 & 64.9 & 62.8 \\
\hline Special care unit, $\%$ & 23.7 & 26.0 & 22.4 & 15.9 \\
\hline \multicolumn{5}{|l|}{ Staffing } \\
\hline$>4.55$ nursing hours/resident-day, $\%$ & 9.5 & 8.6 & 7.9 & 5.6 \\
\hline $\begin{array}{l}\text { Nurse practitioner or physician's } \\
\text { assistant, } \%\end{array}$ & 18.8 & 22.5 & 23.3 & 24.4 \\
\hline $\begin{array}{l}\text { Percent of nurses that are RNs, } \\
\text { mean (SD) }\end{array}$ & $39.8(20.1)$ & $36.6(19.4)$ & $31.8(18.8)$ & $27.3(18.6)$ \\
\hline \multicolumn{5}{|l|}{ Resident payer mix } \\
\hline Percent Medicare, mean (SD) & $8.8(11.8)$ & $9.7(10.5)$ & $9.7(11.7)$ & $8.2(10.1)$ \\
\hline Percent Medicaid, mean (SD) & $54.2(24.6)$ & $60.6(21.7)$ & $67.8(20.2)$ & $78.6(16.7)$ \\
\hline Percent private pay, mean $(\mathrm{SD})$ & $37.0(23.6)$ & $29.7(19.5)$ & $22.4(16.7)$ & $13.1(12.7)$ \\
\hline Resource poor facility*, \% & 4.2 & 6.0 & 12.3 & 32.5 \\
\hline \multicolumn{5}{|l|}{$\begin{array}{l}\text { Number of states with } X \text { number } \\
\text { of NHs within each quartile }\end{array}$} \\
\hline$X=0 \mathrm{NHs}$ & 1 & 2 & 8 & 10 \\
\hline$X=1-9 \mathrm{NHs}$ & 11 & 10 & 5 & 8 \\
\hline$X=10-49 \mathrm{NHs}$ & 21 & 22 & 22 & 11 \\
\hline$X \geq 50 \mathrm{NHs}$ & 15 & 14 & 13 & 19 \\
\hline
\end{tabular}

$\mathrm{NP}=$ nurse practitioner; $\mathrm{PA}=$ physician's assistant.

*Resource poor designation based on overall payer mix.

${ }^{\dagger}$ Each state is represented within each column (quartile) so that the sum of each is 48 . 
Table 3: Multivariable Multi-Level Model Results

\begin{tabular}{lcc}
\hline & $\begin{array}{c}\text { Adjusted } \\
\text { Odds Ratio }\end{array}$ & $\begin{array}{c}\text { 95\% Confidence } \\
\text { Interval }\end{array}$ \\
\hline NH level & & \\
Percent of residents in NH reported black & & \\
$\quad$ 1st quartile (lowest) & Ref & $1.06-1.13$ \\
2nd quartile & 1.10 & $1.10-1.18$ \\
$\quad$ 3rd quartile & 1.14 & $1.15-1.25$ \\
$\quad$ 4th quartile (highest) & 1.20 & $1.11-1.67$ \\
State policies & & \\
$\quad$ Bed hold policy & 1.37 & $0.93-1.00$ \\
Medicaid rate, $\$ 10$ increments & & $0.69-0.87$ \\
$\quad$ For whites & 0.96 & \\
$\quad$ For blacks & 0.78 & - \\
Individual level & & $0.77-0.88$ \\
Race & & $0.91-0.99$ \\
$\quad$ White & Ref & \\
$\quad$ Black & 0.82 & $0.95-0.98$ \\
$\quad$ Other & 0.95 & $0.76-0.94$ \\
Older age, 10 year increments & & \\
$\quad$ For whites & 0.97 & \\
$\quad$ For blacks & 0.85 & $1.13-1.19$ \\
ADL impairment & & $0.91-1.27$ \\
None/mild & Ref & $1.40-1.96$ \\
Moderate & & \\
$\quad$ For whites & 1.16 & \\
$\quad$ For blacks & 1.07 & \\
Severe & 1.25 & \\
$\quad$ For whites & 1.66 & \\
$\quad$ For blacks & & \\
\hline
\end{tabular}

*Adjusted for: market competitiveness, hospital wage index, population over age 75 , hospital beds, per capita income, $\mathrm{NH}$ size, staffing, special care unit, percent of residents Medicare, Medicaid, and self pay, occupancy, profit status, chain membership, education, DNH, DNR, diagnoses, stability of condition, fever, weight and weight change, cognitive impairment, medication use, and hospice. ${ }^{\dagger}$ Race main effect. Applies to younger residents, with no/mild ADL impairment, in states with lower Medicaid reimbursement rates.

$\mathrm{NH}=$ nursing home; $\mathrm{DNR}=$ do not resuscitate $\mathrm{DNH}=$ do not hospitalize; $\mathrm{ADL}=$ activities of daily living.

Three-quarters of states reported a bed hold policy and the average Medicaid per diem payment rate was $\$ 104(\mathrm{SD}=20)$.

Results of the multilevel model are presented in Table 3. It revealed incremental increases in the risk of hospitalization for all residents in a $\mathrm{NH}$ as the percent of black residents in the $\mathrm{NH}$ increased. Residents in states with a bed hold policy were more likely to be hospitalized than were residents in states without a policy (adjusted odds ratio [AOR]: 1.37, 95 percent confidence 
interval [CI]: 1.12-1.68). The effect of the Medicaid rate differed by resident race. When compared with white residents in states with lower Medicaid rates, white residents in states with higher rates ( $\$ 10$ increase) showed a 4 percent decreased probability of hospitalization (AOR: $0.96,95$ percent CI: $0.93-$ 1.00) while black residents showed a 22 percent decreased probability of hospitalization (AOR: 0.78, 95 percent CI: 0.69-0.87).

Both age and ADL impairment modified the effect of resident race on the risk of hospitalization. For younger, minimally impaired residents, blacks had lower odds of hospitalization compared with whites (AOR: 0.82, 95 percent CI: $0.77-0.88)$. With increasing age, the odds of hospitalization were still lower for black (AOR: 0.85, 95 percent CI: 0.76-0.94) compared with white residents (AOR: 0.97, 95 percent CI: 0.95-0.98). Although impairment increased the risk of hospitalization for all residents, the odds were substantially higher for black residents with severe impairment than for similar whites (black AOR: 1.66, 95 percent CI: 1.40-1.96; White AOR: 1.25, 95 percent CI: 1.22-1.29).

\section{DISCUSSION}

We found that the context of $\mathrm{NH}$ care contributed to the differential risk of hospitalization for Black and White residents but that state Medicaid reimbursement policies may have helped to ameliorate that disparity. Across $\mathrm{NH}$ racial composition quartiles, trends in staffing and facility organization were highly suggestive of lower quality in NHs with higher concentrations of black residents. The same pattern emerged in the outcome such that regardless of a resident's own race, risk of hospitalization increased as the percent of residents identified as black in the $\mathrm{NH}$ increased.

Facility resource availability, as measured by the percent of residents on Medicaid, private pay, and a composite descriptor of payer mix, also tracked closely with facility racial profile. Under these conditions, it is not surprising that black residents should benefit more than white residents from higher Medicaid rates. Facilities with resources from private pay residents or other sources are going to be better able to offset the lower revenue generated by Medicaid recipients. When this affords more staff and services, it likely benefits all residents in the NH. However, $\mathrm{NHs}$ with a greater reliance on Medicaid will have fewer overall resources to draw from.

These findings illustrate the role of structural inequities in creating and maintaining racial disparities in $\mathrm{NH}$ care. The correlation between facility racial composition and resource accessibility is, at least partially, perpetuated 
by admission patterns that reflect, or perhaps magnify, underlying community segregation (Reed and Andes 2001; Angelelli, Grabowski, and Mor 2006; Smith and Mor 2006; Smith et al. 2007). While the root of racial disparities in $\mathrm{NH}$ care is complicated, our research suggests that better support of Medicaidreliant NHs could be one mechanism by which to diminish these systemic disparities. This will be increasingly important as the site of long-term care services increasingly shifts to community-based programs and Medicaid NHs are pressed to provide care to more impaired residents.

The persistent difference in hospitalization risk between black and white residents after controlling for contextual factors suggests that individual-level disparities continue to plague $\mathrm{NH}$ quality. That hospitalizations increased with functional impairment is not surprising but the differences between black and white residents were striking, particularly among the most impaired. The amount and type of information that black residents and their families receive, particularly around end-of-life decisions, may partially account for these findings. Mortality follow-back studies have shown that family members of black decedents were less likely to report that death was expected, even if the resident was highly impaired before death (Williams 2006), and more likely to report problems in physician communication than were family members of white decedents (Welch, Teno, and Mor 2005).

There are limitations to this study. We did not differentiate between unavoidable and potentially preventable hospitalizations. Regardless, evidence shows that $\mathrm{NHs}$ with low hospitalization rates have lower percentages of potentially preventable hospitalizations than do NHs with high hospitalization rates (Carter and Porell 2005). Second, our estimates are based on crosssectional data, which could be endogenous in that states with more generous payment rates might have lower rates of hospitalization due to some unknown common factor like state wealth. Third, we did not have individual data on $\mathrm{NH}$ payer source. Valid measures of individual payment would have been useful in teasing out the effects of resident versus $\mathrm{NH}$ resource availability and the implications for disparities in care.

\section{SUMMARY}

This study revealed the influence of individual and organizational factors on the disparate risk of hospitalization for black and white $\mathrm{NH}$ residents. While characteristics that affect individualized care are important, the concentration of black residents in $\mathrm{NHs}$ with the fewest resources is an undeniable contrib- 
utor to racial disparities in $\mathrm{NH}$ quality. That higher Medicaid payment rates reduced the risk of hospitalization substantially more for black than for white residents suggests that efforts to reduce racial disparities in $\mathrm{NH}$ care must include strategies to better support Medicaid-reliant NHs.

\section{ACKNOWLEDGMENTS}

We would like to acknowledge Jacqueline Zinn, David Grabowski, and Mark Schleinitz for their role in developing the study. We would also like to thank Nancy C. Grossman for her assistance in collecting the state policy data and Jeffrey Hiris, Chris Brostrup-Jensen, and Yuwei Cang for help with the data management and analysis. This research was supported by National Institute on Aging grants RO1 AG20557 and RO1 AG23622 (PI on both: Vincent Mor). The data were analyzed under Data Use Agreement No. 12432. Andrea Gruneir was also supported by an AARP Scholar's Award. An earlier version of this paper was presented as a poster at the AcademyHealth Annual Research Meeting in Orlando, Florida in June 2007.

Disclosures: None.

Disclaimers: None.

\section{REFERENCES}

Angelelli, J., D. C. Grabowski, and V. Mor. 2006. "Effect of Educational Level and Minority Status on Nursing Home Choice after Hospital Discharge." American Journal of Public Health 96: 1249-53.

Banaszak-Holl, J., J. S. Zinn, and V. Mor. 1996. "The Impact of Market and Organizational Characteristics on Nursing Care Facility Service Innovation: A Resource Dependency Perspective." Health Services Research 31: 97-116.

Bernabei, R., G. Gambassi, K. L. Lapane, F. Landi, C. Gatsonis, R. Dunlop, L. Lipsitz, K. Steel, and V. Mor. 1998. "Management of Pain in Elderly Patients with Cancer. SAGE Study Group." Journal of the American Medical Association 279: 1877-82.

Caralis, P. V., B. Davis, and K. Wright. 1993. "The Influence of Ethnicity and Race on Attitudes toward Advance Directives, Life-Prolonging Treatments, and Euthanasia." Journal of Clinical Ethics 4: 155-65.

Carter, M. W., and F. W. Porell. 2005. "Vulnerable Populations at Risk of Potentially Avoidable Hospitalizations: The Case of Nursing Home Residents with Alzheimer's Disease." American Journal of Alzheimer's Disease and Other Dementias 20: $349-58$.

Culler, S. D., M. L. Parchman, and M. Przybylski. 1998. "Factors Related to Potentially Preventable Hospitalizations among the Elderly." Medical Care 36: 804-17. 
Degenholtz, H., R. Arnold, A. Meisel, and J. Lave. 2002. "Persistence of Racial Disparities in Advance Care Plan Documents among Nursing Home Residents." Journal of the American Geriatrics Society 50: 378-81.

Dula, A. 1994. "African American Suspicion of the Health Care System Is Justified: What Do We Do about It?" Cambridge Quarterly of Health Care Ethics 3: 347-57.

Fries, B. E., D. P. Schneider, W. J. Foley, M. Gavazzi, R. Burke, and E. Cornelius. 1994. "Refining a Case-Mix Measure for Nursing Homes: Resource Utilization Groups (RUG-III).” Medical Care 32: 668-85.

Gambassi, G., K. L. Lapane, A. Sgadari, F. Landi, P. Carbonin, A. Hume, L. Lipsitz, V. Mor, and R. Bernabei. 1998. "Prevalence, Clinical Correlates, and Treatment of Hypertension in Elderly Nursing Home Residents. SAGE Study Group." Archives of Internal Medicine 158: 2377-85.

Grabowski, D. C., Z. Feng, O. Intrator, and V. Mor. 2004. "Recent Trends in State Nursing Home Payment Policies.” Health Affairs, Suppl Web Exclusives: W4: 363-73.

Gruneir, A., S. C. Miller, O. Intrator, and V. Mor. 2007. "Hospitalization of Nursing Home Residents with Cognitive Impairments: The Influence of Organizational Features and State Policies." Gerontologist 47 (4): 447-56.

Harada, N. D., A. Chun, V. Chiu, and A. Pakalniskis. 2000. "Patterns of Rehabilitation Utilization after Hip Fracture in Acute Hospitals and Skilled Nursing Facilities." Medical Care 38: 1119-30.

Hopp, F. P., and S. A. Duffy. 2000. "Racial Variations in End-of-Life Care.” Journal of the American Geriatric Society 48: 658-63.

Intrator, O., N. G. Castle, and V. Mor. 1999. "Facility Characteristics Associated with Hospitalization of Nursing Home Residents: Results of a National Study." Medical Care 37: 228-37.

Intrator, O., D. C. Grabowski, J. Zinn, M. Schleinitz, Z. Feng, S. Miller, and V. Mor. 2007. "Hospitalization of Nursing Home Residents: The Effects of States' Medicaid Payment and Bed-Hold Policies." Health Services Research 42 (4): 1651-71.

Intrator, O., and V. Mor. 2004. "Effect of State Medicaid Reimbursement Rates on Hospitalizations from Nursing Homes." Journal of the American Geriatrics Society 52: 393-8.

Intrator, O., J. Zinn, and V. Mor. 2004. "Nursing Home Characteristics and Potentially Preventable Hospitalizations of Long-Stay Residents." Journal of the American Geriatric Society 52: 1730-6.

Lapane, K. L., H. H. Fernandez, and J. H. Friedman. 1999. "Prevalence, Clinical Characteristics, and Pharmacologic Treatment of Parkinson's Disease in Residents in Long-Term Care Facilities." Pharmacotherapy 19: 1321-7.

Miller, S. C., G. Papandonatos, M. Fennell, and V. Mor. 2006. "Facility and County Effects on Racial Differences in Nursing Home Quality Indicators.” Social Science and Medicine 63: 3046-59.

Mitchell, S. L., J. M. Teno, O. Intrator, Z. Feng, and V. Mor. 2007. "Decisions to Forgo Hospitalization in Advanced Dementia: A Nationwide Study." Journal of the American Geriatrics Society 55: 432-8. 
Mor, V. 2004. "A Comprehensive Clinical Assessment Tool to Inform Policy and Practice. Applications of the Minimum Data Set.” Medical Care 42: III-50-III-59. Mor, V., G. Papandonatos, and S. C. Miller. 2005. "End-of-Life Hospitalization for African American and Non-Latino White Nursing Home Residents: Variation by Race and a Facility's Racial Composition." Journal of Palliative Medicine 8: 5968.

Mor, V., J. Zinn, J. Angelelli, J. M. Teno, and S. C. Miller. 2004. "Driven to Tiers: Socioeconomic and Racial Disparities in the Quality of Nursing Home Care." Milbank Quarterly 82: 227-56.

Morris, J. N., B. E. Fries, D. R. Mehr, C. Hawes, C. Phillips, V. Mor, and L. Lipsitz. 1994. "MDS Cognitive Performance Scale." Journal of Gerontology 49: M174-82.

Morris, J. N., B. E. Fries, and S. A. Morris. 1999. "Scaling ADLs within the MDS." Journal of Gerontology. Series A, Biological Sciences and Medical Sciences 54: M546-53.

O'Brien, L. A., J. A. Grisso, G. Maislin, K. LaPann, K. P. Krotki, P. J. Greco, E. A. Siegart, and L. K. Evans. 1995. "Nursing Home Residents' Preferences for LifeSustaining Treatments." Journal of the American Medical Association 274: 1775-9.

Reed, S. C., and S. Andes. 2001. "Supply and Segregation of Nursing Home Beds in Chicago Communities." Ethnicity and Health 6: 35-40.

Seidman, B. 2002. "A Briefing Chartbook on Shortfalls in Medicaid Funding for Nursing Home Care." Report Prepared for the American Health Care Association.

Shepardson, L. B., H. S. Gordon, S. A. Ibrahim, D. L. Harper, and G. E. Rosenthal. 1999. "Racial Variation in the Use of Do-Not-Resuscitate Orders." Journal of General Internal Medicine 14: 15-20.

Smith, D. B., V. Mor, Z. Feng, M. Fennell, and J. Zinn. 2007. "Separate and Unequal: Racial Segregation and Disparities in Quality across Nursing Homes in the United States." Health Affairs 26 (5): 1448-58.

Smith, L. M., and V. Mor. 2006. "Race and Geography: Disparities in Choice and Access to Nursing Homes. Does Distance Matter?" Poster presented at the Gerontological Society of America Annual Scientific Meeting, November 16-20, 2006, Dallas.

Spooner, J. J., K. L. Lapane, A. Hume, V. Mor, and G. Gambassi. 2001. "Pharmacologic Treatment of Diabetes in Long-Term Care." Journal of Clinical Epidemiology 54: 525-30.

Welch, L. C., J. M. Teno, and V. Mor. (2005). "End-of-Life Care in Black and White: Race Matters for Medical Care of Dying Patients and Their Families." Journal of the American Geriatrics Society 53: 1145-53.

Williams, B. A., K. Lindquist, S. Y. Moody-Ayers, L. C. Walter, and K. E. Covinsky. 2006. "Functional Impairment, Race, and Family Expectations of Death." Journal of the American Geriatrics Society 54 (11): 1682-7.

Won, A., K. L. Lapane, G. Gambassi, R. Bernabei, V. Mor, and L. A. Lipsitz. 1999. "Correlates and Management of Nonmalignant Pain in the Nursing Home. SAGE Study Group. Systematic Assessment of Geriatric Drug Use via Epidemiology." Journal of the American Geriatrics Society 47: 936-42.

Zinn, J. S. 1994. "Market Competition and the Quality of Nursing Home Care.” Journal of Health Politics, Policy and Law 19: 555-82. 